\title{
PUEBLOS DE MAR DE RECASENS: ENTRE ETNOGRAFÍA Y LITERATURA ${ }^{1}$
}

Peoples of sea by Recasens: Between Ethnography and Literature

$45-58$

Iván Carrasco M.*

Resumen

Pueblos de mar. Relatos etnográficos es un libro singular que forma parte de una clase de textos ambivalentes entre la escritura etnográfica y la literatura antropológica, género nuevo en las letras chilenas paralelo a la llamada antropología poética. Esta condición depende de los diversos metatextos que lo conforman en gran parte, tales como el título, subtítulo, prólogo, estructura y especificidades textuales, que reconocen expresamente su plural condición de texto etnográfico y literario. Al mismo tiempo, su narración referencial se mezcla con subjetividad, autorreflexividad y ficcionalidad.

Palabras clave: Etnografía, literatura, metatexto, ficcionalidad.

Abstract

Peoples of sea. Ethnographic accounts is a unique book that is part of a class of ambivalent textual writings between ethnographic and anthropological literature, a new gendre in Chilean letters parallel to the so-called poetic anthropology. This condition depends on the different metatexts that compriseit, such as title, subtitle, prologue, and specific textual structures, which expressly recognize plural condition of ethnographic and literary text. At the same time, his referential discourse is mixed with subjectivity, self-reflexivity and fictionality.

Key words: Ethnography, literature, metatext, fictionality.

\section{UN TEXTO COMPLEJO Y PLURAL}

Andrés Recasens Salvo es un destacado antropólogo social y académico chileno, escritor de etnografía y de literatura para adultos y niños. Es iniciador y mentor de la Antropología poética y de la Literatura antropológica. En el ámbito literario sus publicaciones son Cinco Nocturnos (Poemas), 1966; Oratorio para observador, hombre exhausto y coro de astronautas (Poema). 1968. Bamberg. Bilingüe español-alemán, 1993; Epístolas espaciales (Poemas), 1970; Evangelio según San Mateo (monólogo), 1980; Eco-Poemas y Otras Ecologías. Antología: Poesía. Narrativa. Teatro, 2011.

El libro Pueblos de mar. Relatos etnográficos (2003) es un estudio de los mareros, trabajadores que extraen recursos vivos del mar y según ellos son llamados

\footnotetext{
${ }^{1}$ Este trabajo forma parte del Proyecto Fondecyt Regular No 1100344 "Literatura antropológica en Chile".
} 
buzos, algueros, pescadores, salineros; seres humanos explicados en su cultura, su ambiente, su historia, su quehacer. Este libro es un modelo de monografía antropológica por su precisión en el manejo del género, los contenidos disciplinarios, el estilo riguroso y atrayente, la perspectiva y los elementos de literatura que incluye de modo coherente. También es un texto magistral por su ambivalencia, pues respeta las reglas de la escritura antropológica clásica en una dimensión del texto, al mismo tiempo que en otra agrega elementos de orden literario, como un estilo connotativo y sincrético, diversos tipos de discurso intercalados, no a modo de fragmentos, sino mediante la transformación del estilo en cada caso, un cierto carácter de texto inacabado, un narrador que expresa su sensibilidad, sus afectos, su compromiso con los pescadores a quienes considera su prójimo.

La configuración del volumen como texto de investigación o estudio incluye varios elementos: portada, prólogos del autor y de Sergio González, XXI capítulos; el título se refiere al objeto de estudio, es decir, a las personas en su ambiente, gente de mar, con la cual va a convivir un antropólogo en terreno, y un subtítulo (Genette, 5158) donde se establece el género o tipo de discurso principal, el relato etnográfico, que sistematiza teórica o científicamente las experiencias del antropólogo o arqueólogo transformándolas en conocimiento. Formalmente, ello remitiría a una dimensión antropológica que implicaría la escritura de un texto referencial, en el sentido de Morales: género discursivo en que el autor y el sujeto de la enunciación o narrador son el mismo y que opera con un referente extratextual de diversa identidad, a diferencia del texto ficcional (11). Otro elemento es la contraportada, en que se define en forma sintética el carácter y sentido del libro: el narrador define a los pescadores artesanales, la cultura de los pueblos, se refiere a la depredación actual y explica indirectamente a sus textos como literarios, esto último en una actitud metatextual que se reitera en diversos sectores del volumen, como al final de su "Introducción", en "El cuaderno de campo" (Recasens, 46-47), "La comunidad intersubjetiva", "La observación participante" (id. 117-119), "La seducción" (ibid. 157-164), entre otros:

"El cuaderno de campo, en décadas pasadas, recogía todo el acontecer del antropólogo en el terreno. Y sus anotaciones cubrían observaciones y conversaciones, su recorrer atento por los ambientes y paisajes, su participación en los grupos y en sus actividades, su asistencia a eventos, ceremonias y rituales. Pero además de recoger el fruto del trabajo del etnógrafo, era una especie de lienzo en donde se plasmaban sensaciones, sentimientos y emociones, situaciones imprevistas y malentendidos; sus descubrimientos, alegrías y frustraciones; pensamientos íntimos, hondos y fugaces que iban surgiendo de los estados de ánimo diversos que este sufría. Era, en esencia, un "diario de vida" (Recasens, 46).

Curiosamente, a pesar de seguir el modelo del texto científico, Pueblos de mar... carece de un capítulo específico claramente definido como conclusiones, cierre, resultados, que sería lo esperable. Esto resalta la condición literaturizante del 
libro, pues la posibilidad de carencia de un final obligatorio es característico de la novela y de los textos narrativos; los textos literarios pueden elegir el cierre, un final coherente con la historia contada o inesperado o simbólico o metafórico, o abierto o un nofinal, una narración en suspenso.

En forma paralela, Sergio González en su prólogo "La Antropología como sistematización de la Alteridad" ha hecho una comprensiva y sensible reseña del volumen. En él destaca la permanente reflexión de Recasens sobre el otro, la alteridad en relación con la identidad, las tramas de la cultura, la reconversión del rapport entre agente externo y comunitario como seducción mutua, el paso desde la entrevista en profundidad a la conversación a profundidad, el encuentro/desencuentro entre tradición y modernidad. También, a las "licencias" que Recasens se ha dado para escapar del formato de informe de investigación o del libro para estudiantes iniciales: la combinación de la mirada del antropólogo que reflexiona con el relato literario reflejo de un mundo inédito, el sincretismo en el estilo que proyecta una recepción amena y entusiasta, hacer literatura a modo de collage a partir de los cuadernos de campo, notas tomadas en terreno y elaboradas en el gabinete para recrear la experiencia y sistematizar el mundo cultural narrado, el trabajo etnográfico como material para hacer literatura. Además, Recasens al final de su "Introducción" expresa que ha utilizado relatos y otras formas literarias, que ha ocultado nombres verdaderos e inventado otros, que sus relatos, diálogos, apuntes, testimonios, conversaciones normales y a profundidad que conforman el volumen, no son solo de índole científica, antropológica, sino también artística, literaria. Por lo tanto, se puede inferir que conforman textos ficticios y, por ello, literarios (Martínez Bonati, 177-203; Mignolo, 58-74).

\section{EN LA OTREDAD DE LOS MAREROS}

Pueblos de mar relata historias de un grupo social, los mareros, sus familias, sus trabajos y sus días. Este es un mundo reducido, cotidiano, monótono, en cierta medida una identidad nueva y particular, derivada de la mezcla de naturaleza y cultura, definida por el trabajo y la forma de vida distinta a la que surge de la aglomeración de la ciudad, es la otredad que busca el antropólogo.

El tema central del libro Pueblos de mar... es la identidad característica de este grupo humano visto como alteridad, pero ello supone un desplazamiento anterior del observador en el espacio y el tiempo, es decir, un viaje de conocimiento, el viaje a la otredad característico de la literatura y de la etnografia. En forma más precisa, pienso que el viaje del relato antropológico y arqueológico se puede considerar una variedad del viaje intelectual del siglo XX estudiado por Colombi (14-21). Esta investigadora ha propuesto que el relato de viaje es un discurso de autoridad que propone, refuta, polemiza, escribe contra el falso viajero que perpetúa los errores sobre un determinado espacio, inventa una cultura, es un antiguo género literario o discursivo, copioso imaginario privilegiado por la ficción, práctica ligada a la ciencia y la expansión territorial de Occidente, su alcance es la cultura del viaje. El viaje 
intelectual está relacionado con escritores latinoamericanos de 1880-1915, operaciones de traslación y traducción de sus escritos, saber cosmopolita $\mathrm{y}$ modernizado, textos afines con una práctica espacial que daban cuenta de un desplazamiento entre destinos, lenguas, tiempos, contextos. El viaje-desplazamiento debe implicar una escritura desterritorializada o externa y si incluye pasaje a otra lengua, extraterritorial (Colombi, 13-15). La emigración intelectual se manifiesta en destierros y exilios, el desplazamiento pone a prueba la autofiguración del sujeto y su pertenencia a una cultura periférica. "El viaje intelectual/.../ señala al escritor que se autorrepresenta como agente de una cultura e interviene como tal en una escena pública exterior" (id.16); el escritor viajero, migrante o residente se comporta como un inventor de nuevas representaciones metropolitanas, mediador cultural, agente modernizador, además de organizar un mapa que la modernidad ha redistribuido y relocalizado. Los narradores antropólogos viajan desde y hacia la cultura, el conocimiento, el saber propio y ajeno, revalidan el conocimiento local, pero sin tratar de modificarlo. "Toda escritura viajera es un lugar de convergencia y dispersión de saberes: fuga de un centro y profusión temática son sus características más constantes/.../ Una buena parte de esta escritura se caracteriza por su estructuración episódica, su resolución en el camino, su propensión a la digresión - tenida como quiste textual en otros géneros $\mathrm{y}$, sin embargo, medular a este sistema- (ibid. 18). La ley del género, dice Colombi, es: el que escribe es el que viaja.

Más que el viaje mismo que lleva a otro lugar, algo casi obvio pero no por ello menos importante, Recasens destaca los lugares poblados, los trabajos realizados y las personas que trabajan en y con el mar, buscando en ellos lo propio del género humano. Ese es el trabajo del antropólogo, conocer seres y comunidades que formen parte de la otredad, para efectos de conocimiento, posteriormente docencia y/o publicaciones, con fines y motivaciones profesionales, investigaciones, proyectos de visita, publicaciones. El viajero de Recasens ha salido desde la capital impulsado por su necesidad de conocer personas, lenguajes, oficios, modos de vivir distintos a los habitantes de la ciudad. Según Augé, el problema ¿Quién es el otro? constituye el fondo del debate antropológico; su tarea consiste en determinar el documento de la identidad y la alteridad relativas (13-33).

El viaje antropológico de Pueblos de mar... presentado por Recasens es individual, a veces acompañado por algún discípulo o estudiante, pero no para quedarse en un mismo espacio, sino para recorrer lugares diferentes por períodos variados, según el recibimiento, el clima, etc., para encontrar experiencias de lo que llamamos humanidad. Para ello recorre lugares físicos diferentes, como Boyecur, Vichuquén, Lenga, La Lancha, Bucalemu, Laraquete, reconocibles como lugares existentes, históricos, observa actividades como la pesca sin anzuelo, con caña, industrial, el trabajo en las salinas, la caza con guachis, conversa con mujeres, ancianos, adultos, personas solas, familias, grupos etáreos como jóvenes y niños, conoce personificaciones del mar (hombre, mujer, padre, patrón), escucha leyendas, estudia la formación del pescador, un 
lance en la laguna, las migraciones estacionales, el agotamiento de los recursos, el entierro simbólico, el cabildo, los botes a motor, los nuevos roles en la comunidad - de aldea a caleta de pescadores-, entre otros hechos, aspectos, episodios. El viaje etnográfico implica un saber disciplinario de orden antropológico y/o arqueológico, el manejo de metodologías variadas, entre la que destaca la "observación participante" y la entrevista en profundidad, lo que permite tomar conciencia de la escritura literaria de carácter etnográfico. A partir de una anécdota, el narrador dice:

... aunque no es común, esta anécdota que me aparece en el otro lado me vino de este lado, después de atravesar cerros y lagunas me aparece en el otro lado con tal similar textura, que no es posible dejar de emparentarla con la anterior, y de aquí y de allá debo ir construyendo el relato que las asuma. Y la construcción puede devenir en un cuento, pero sin dejar de hacer correr dentro de él no solo la trama que lo arquitectura, la música, el ritmo en la prosa que bordea la literatura, sino de manera primordial el tejido de interacciones que la anécdota traía y los usos y costumbres implicados, la adhesión a valores, las prescripciones que tejían una relación que se daba al centro o, por el contrario, en los bordes de un encuentro luminoso entre diferencias (Recasens, 119).

¿Por qué este antropólogo ha elegido un mundo de pescadores?... tal vez por su valor simbólico, seres que viven entre el agua, la tierra y el cielo, de lo que surge su sentido polisémico, su sentimiento ambivalente, tal vez su condición de mediadores identitarios, seres de origen terrícola con posibilidad de transformación en viajes de ida y vuelta, símbolos del gran viaje, hombres, mujeres, niños, ancianos, jóvenes, que construyen el gran relato de la pesca y la recolección en el mar y la playa de la vida. Y que da origen a una literatura antropológica de la cotidianidad de las identidades y alteridades, el prójimo, el mundo que se construye en la observación mediante la interacción programada y consciente del antropólogo.

\section{LA NARRACIÓN AMBIVALENTE}

Este libro está conformado por dos ejes textuales, uno semántico científico y otro literario, por lo que conforma un relato ambivalente. El título global de este libro intenta retratar, a partir de datos de valor etnográfico y opiniones de fundamento etnológico, una forma significativa de vida, la vida de los pescadores artesanales, los mareros y mareras, personas que viven del mar, lo aman, lo respetan y le temen, le agradecen por los recursos que les entrega, a pesar de los ingentes esfuerzos que para ello deben realizar:

Cuando se habla, en general, de pescadores artesanales, la referencia es a todas aquellas personas que habitan en localidades de nuestro litoral y que desarrollan indistintamente actividades de captura (pesca), de extracción (marisquería) o de recolección de algas (alguería). Cualquiera de estas actividades puede ser realizada con un mayor énfasis que las otras, dependiendo de la localidad, de los recursos disponibles, del grado de especialización de los mareros y del tipo de 
tecnología que utilizan, como también de la posesión de habilidades y aptitudes físicas que supone el desempeño de cada una de ellas. El hombre de mar puede ser al mismo tiempo buzo, alguero y pescador, la mujer, en general, se desempeña como alguera (15).

Los hombres de mar conforman una sociedad temporal, mientras tienen trabajo y viven en un lugar determinado, construyendo allí su cultura, dialecto, familia; el plural del sustantivo base (pueblos) indica esta orientación, son los Otros portadores de una cultura distinta, de acuerdo con el eje científico que organiza la perspectiva que construye ese mundo.

El otro eje, paralelo y superpuesto, concatenado, más discursivo, retórico, estilístico, es el literario, señalado por distintos metatextos al mismo tiempo que por la misma narración, los temas, etc., debido a la polivalencia global del texto. El título del libro puede corresponder a una descripción o narración etnográfica, pero también a una novela, a un conjunto de cuentos, a una serie de cuadros costumbristas. El título doble, título y postítulo, es la especificación precisa de la condición interdisciplinaria e intercultural del volumen, referencial, denotativo, a la vez que emocional, connotativo; remite a los dos tipos de elementos que configuran el texto como conjunto.

$\mathrm{Y}$ coincide con lo que hemos llamado literatura antropológica (Carrasco y Alvarado, 9-23), textualidad que forma parte de un área fluctuante de discursos tradicionales (crónicas, autobiografías, diarios de viaje) y otros más nuevos (testimonios, poemas prosaicos, narrativa cotidiana) que fluctúan en las fronteras textuales entre incorporarse al canon literario o al científico-social o intentar tener éxito fuera de ellos; es una variedad de escritura que a veces abandona por falta de interés o desconocimiento las bellas letras, conformando una "estilística del prosaísmo", una "retórica de lo cognitivo, referencial", a veces un estudio autobiográfico, conjuntos variables de textos, estilos y discursos, desplazamientos entre opciones, saber o arte, ciencia o literatura, discurso desde un saber profesional disciplinario o discurso de un saber intuitivo, trascendente, que sobrepasa los límites de la razón, las lógicas y conceptualizaciones científicas, al apostar a la creación y la belleza. Un rasgo propio de esta clase de texto literario es su ambivalencia genérica, que posibilita su lectura como texto literario - texto literario antropológico- y como etnografía vanguardista - antropología literaria-.

La narración del texto Pueblos de mar... está controlada por un narrador complejo que, además de explicar las situaciones y actos comunicativos, monologa, comenta, infiere, saca conclusiones, incita a sus interlocutores a contarle aspectos de sus vidas, escucha con atención, reflexiona:

"La televisión ha introducido en los pueblos un tipo de gasto que presiona sobre el presupuesto familiar. Es un consumo de mercancías que no corresponde a los modos de vida de las localidades. Pero con la particularidad que presiona desde dentro de los propios hogares (Recasens, 64). 
En este libro no hay narración lineal, sino una serie de diálogos entre un antropólogo con sus nuevos amigos, los pescadores, durante su trabajo de campo. Por lo tanto, estos textos son observaciones parciales ordenadas en grupos o secciones regidas por un título que les da cohesión y sentido, porque separados son relatos que significan o representan algo (una aventura, una conducta, un aprendizaje), pero junto a otros carecerían de sentido si no fuera por el título. Constituyen una especie de collage: el volumen está dividido en capítulos heterogéneos que se refieren a temas variados aunque relacionados con su vida, su trabajo, su situación existencial, sus deseos, quejas, etcétera.

\begin{abstract}
'Sí, ya veo, don Andrés. En su cara leo lo que le perturba. ¿Que por qué no intenté ver a mi hijo? ¿Por qué no traté de tener mando sobre él? Pero ¿Qué quería que yo hiciera? Se lo llevaron fuera del país, no sé cómo lo hicieron, pero no lo inscribieron con mi nombre. Y ahora han pasado más de diez años. Sería como tratar de pegar un molusco a una roca en la que no se ha criado. Se despega al tiro y se va con el mar para morir. Estoy seguro que el niño llegará a ser un hombre de bien porque ella es una mujer de ley, y eso me basta" (Recasens, 60).
\end{abstract}

Estos minirrelatos estarían aislados si no formaran parte de la cadena de la observación participante, aunque no carecen de un relativo grado de independencia. No se trata de narraciones enmarcadas en sentido estricto, pues no dependen de un narrador básico y único que acepte y dé un espacio en el relato a otros narradores, sino más bien de un sujeto que dialoga con otros que pasan a ser también sujetos de una "enunciación reducida", repartida en muchas dimensiones, contactos, temas, lenguajes, lo que conforma el texto global como un gran collage.

Aquí se demuestra un rasgo significativo del sujeto, su ruptura del modelo clásico del narrador antropólogo objetivo y neutro, al tiempo que confirma y aumenta lo anterior mediante la presencia de ciertos discursos desgajados del trabajo principal, que a veces corresponden más a preocupaciones personales del antropólogo, vinculados con la religión cristiana católica (se refiere a santo Tomás, san Agustín, Teilhard de Chardin, Capítulo XVI "Apuntes") y con la preocupación teórica; lo mismo sucede con "Las ideas-fuerza", o "De intersubjetividades": el antropólogo conversa con su Ayudante universitario sobre la seducción, un metadiscurso relacionado con la interacción característica de la tarea antropológica, pero alejado en este caso del tema específico del volumen.

El narrador a veces habla como antropólogo poniendo en práctica el método de observación participante: "hemos terminado la faena", acota. Así como los pescadores son la Otredad para el antropólogo, más conocedores de su hábitat, con mayor cultura marina, Recasens es el Otro para ellos, con más cultura citadina, más contactos con autoridades, más experiencia y trámites, mayor autoridad, mejor uso del lenguaje, que los puede orientar, ayudar, servir de nexo, hacer lo que ellos no pueden o se les hace dificultoso. "En mí hay otro adentro, al que no entienden, aunque lo respetan" (Recasens, 67). Ese otro es el antropólogo que en forma permanente realiza la función 
propia de su profesión, escuchar y observar a los otros, como un confesor laico o un psiquiatra que sale a buscar pacientes, a la inversa del psicólogo o psiquiatra que atienden en su oficina a quienes lo van a ver. El antropólogo atiende en la vida diaria, el restaurante, la plaza del pueblo son su oficina. Escucha, observa y analiza para aprender, conocer y tal vez ayudar, a menudo más cercano al sacerdote que a los psicólogos o psiquiatras: alguien le enseñó de modo teológico y metodológico, a escuchar. La experiencia, la paciencia y la vocación le dieron su saber práctico. El antropólogo trabaja en motivar conversaciones, mirar, escuchar lo que hacen otros, copiar datos, detalles, en un "diario de campo" y luego desarrollar y redactar esos apuntes en un género determinado (poema, relato, informe, ponencia, artículo).

El discurso del narrador de Pueblos de mar... es letrado, su léxico es amplio, preciso, técnico, propio de un sujeto formado profesionalmente que corresponde al método clásico de la antropología, la observación participante (Recasens, 117-120). Esta clase de narración depende de la perspectiva de un especialista en observar y escuchar, hacer preguntas específicas para inducir a hablar, a conversar. Por ejemplo, le consulta a un grupo amplio si le han puesto nombre al pasaje principal que forma la separación de los rucos en un sector determinado, sabiendo que no lo han pensado (id., 79). Se trata de textos antropológicos, entonces, pero él mismo ha señalado en su "Introducción" que no habla de seres específicos, que les cambia el nombre, etc., lo que significa que son seres ficticios como los de la literatura según Martínez Bonati y Mignolo:

"Lo que llamamos literatura en sentido estricto (las "bellas letras", la poesía) constituye un discurso tan ficticio como un personaje de novela o una historia imaginada. Y puesto que es mera imaginación, puede este discurso ser realista $\mathrm{o}$ fantástico en varios grados" (Martínez Bonati, 8).

Pueblos de mar... se refiere a seres y realidades humildes, populares, trabajadores, pero no por ello se trata de un relato folclórico (Cortázar, 5-35) y aunque se parece en algunos aspectos al tipo de narrador del relato popular que propone Benjamin:

/.../ el narrador tiene cabida junto al maestro y el sabio. Tiene consejo que dar no como el proverbio: para algunos casos, sino como el sabio: para muchos. Es que le está dado remontarse a una vida entera (una vida, además, que no solo encierra la propia experiencia, sino también no poco de la ajena. Lo que ha aprendido de oídas se suma también a lo más propio del narrador). Su don es poder narrar su vida, su dignidad, poder narrar toda su vida (Benjamin, 9596).

Este autor establece para el relato popular la preeminencia de un tipo de narrador que es un sujeto empírico, histórico, sin considerar la naturaleza ficticia de muchos textos, con el cual el narrador del relato antropológico de Recasens coincide en que puede ser maestro, ayudar a algunas - no muchas - personas, apropiarse de alguna experiencia ajena, pero estudiado y aprendido 
sistemáticamente y no de oídas y no narra su vida, sino su conocimiento. El narrador de Recasens no tiene el don de contar su vida en cuanto antropólogo, sino la de sectores sociales determinados. Su don no es contarse a sí mismo, sino escuchar. En cuanto narrador literario puede contar cualquier vida, incluso la suya, pero su narración es simultáneamente antropológica y literaria.

$\mathrm{Su}$ relato no es solo cuento popular o novela, sino un relato de otra índole, disciplinariamente fundamentado, y una narración de lo que "otros" hacen y una escucha de lo que "otros" dicen. El narrador antropólogo o arqueólogo en cuanto tal es muy detallista, lo que depende de la actitud científica, profesional y didáctica del trabajo etnográfico; habla a partir de textos teóricos y metodológicos, se mantiene en su subjetividad como observador permanente, reflexiona y conversa en función de temas antropológicos, su expresión verbal y escrita es precisa. Ello explica las descripciones frecuentes, la gran cantidad de detalles en apariencia sin sentido, pero que se están guardando para un posible análisis de un problema antropológico o arqueológico. En este sentido, la visión del narrador se parece a la de un voyeurista por la concentración en su objeto de estudio, su dedicación, el ocultamiento de su propia identidad para conocer a fondo a los otros, pero además es un observador comprometido, como propone González en su prólogo:

El ojo del antropólogo es el ojo del voyeurista comprometido con esos pescadores, con las minucias de la relación y con la amplitud del respetuoso encuentro que implica la etnografía con realidades que se despliegan (Recasens, 13).

Esto cambia profundamente todo. El narrador de Pueblos de mar... es, sobre todo, un narrador ambivalente, pues no se mantiene en el espacio identitario de un antropólogo clásico como Malinowski, por ejemplo, sino de un sujeto sensible, con sentimientos variados hacia sus observados, que se compromete con sus proyectos, como el cabildo abierto de Bucalemu por ejemplo (221-238), por lo que no es un mero voyeurista.

En la narración del relato literario antropológico existe un doble nivel y, por tanto, un doble tipo de sujeto, uno singular, el narrador, y otro plural, la serie de personas que establecen relación con él, los dialogantes, que narran sus propias historias constituyéndose también en narradores. Como la acción principal de esta interacción verbal es el diálogo, el narrador establece una especie de doble juego: actúa como narrador y asume el papel de dialogante con personajes que ya forman parte de la diégesis (en el sentido de Genette y de Filinich (31-83). Así, se produce una relación asimétrica en el diálogo del relato antropológico entre el consultor que representa el conocimiento científico, el arte, y el consultado, el hombre común que lleva consigo la experiencia cotidiana de la vida.

El narrador que actúa como protagonista es un sujeto entre dos mundos: entre la academia y el mundo cotidiano seleccionado, elegido, encontrado, por tanto, reducido. Este narrador no es objetivo o neutral, psicológica y emotivamente 
vacío, sino una persona, un narrador "lleno" de sí mismo y de la exterioridad. En su conciencia está toda la información que emite y proyecta, ella incluye textos de su agrado como versos de Antonio Machado "Todo el que camina anda/ como Jesús sobre el mar/.../ Caminante, no hay camino,/ sino estelas en la mar"; de Mistral "El mar sus millares de olas/ mece, divino/ Oyendo a los mares amantes/ mezo a mi niño"; de Hernández, "En el mar halla el agua su paraíso ansiado/ y el sudor su horizonte, su fragor, su plumaje". Estas citas las coloca a pie de página para expresar sus estados de ánimo, sus opiniones, su conocimiento. Mantiene la metodología científica, pero no a modo de un sujeto imparcial, sino de una persona que incluye un punto de vista o actitud de participante efectivo, preocupado de los problemas de los otros y de la ayuda que puede prestar.

El punto de vista del narrador del relato literario antropológico corresponde a un profesional especializado en la observación de seres y grupos humanos y sus acciones en la cotidianidad, por lo que su observación está fundada y modelizada por conceptos característicos de las ciencias sociales, consciente de su disciplina y de la necesidad de superarla. Pero la experiencia personal no se puede traspasar, la verdadera confesión se realiza con personas de responsabilidad propia, no de otra persona.

Por ello, el relato literario antropológico es también una serie de textos narrativo-descriptivos que incluyen y/o transcriben una conversación, una reflexión o comentario del narrador, en otras palabras, un texto que habla no solo de referentes externos, mostrados de modo científico, del tema, mundo o historia del texto, sino también del narrador en cuanto sujeto de la enunciación, de su interioridad, sus anhelos, sus sentimientos. "En mí hay otro adentro, al que no entienden, aunque lo respetan" (Recasens, 67). Ese otro es el antropólogo que en forma permanente realiza la función propia de su profesión, escuchar y observar a los otros, como un sacerdote o confesor laico que sale a buscar pacientes, a la inversa del psicólogo o psiquiatra que atienden en su oficina. El antropólogo atiende en la vida diaria, los asientos de restaurante, de la plaza del pueblo, son su oficina. Escucha, observa y analiza para aprender, conocer y tal vez ayudar, más cercano al sacerdote que a los psicólogos o psiquiatras; alguien le enseñó de modo teórico, teológico y metodológico a escuchar; la experiencia, la paciencia, la vocación, le dieron su saber práctico.

Esto es lo que se establece como base de cualquier encuentro transitorio y trivial. Se inicia con la experiencia del extranjero, pero la actitud nuestra no es la de quedar en el papel del extraño, sino la de abrirse a la transformación en un prójimo, haciendo desaparecer al intruso /.../ En este ritual de la interacción /... / que es lo que busco, la ruta que inicia el camino hacia una conversación intencionada, desde lo central de ambos actores, para irla convirtiendo en una conversación a profundidad que amarre los primeros nudos por el significado y sentido que logra alcanzar/.../ es habla y mirada, es gesto y aliento, intención y anhelo de llegar con lo que se tiene en el alma y se 
trata de ir más allá de las palabras, pues hay veces que estas quedan pobres alas para tanto vuelo /.../ Y mediante toda esa complejidad con la de hoy que aún vibra en mis manos al escribirla y la de ayer y la de otros días, voy conformando un relato. Pues no siempre hay la posibilidad de construir un camino unívoco que vaya de una sola conversación a un solo relato. A veces este contiene un ramillete de conversaciones y, otras veces, la conversación o el diálogo pueden contener un ramillete de relatos (118-119).

\section{ENTRE INFORME Y NOVELA}

El estilo con que Recasens relata es complejo, pues incluye diversos rasgos coherentes con la temática desarrollada. El punto de partida del estilo fue el término stilus, transformado en escritura y luego en expresión literaria, relacionado con géneros ampliamente codificados, maneras de hacer según reglas, principios como la virtud humana, originalidad excéntrica, desprecio por los modelos, modo de formar, etc. Hablar de estilo es referirse a cómo está hecha la obra, cómo y por qué suscita cierta clase de recepción (Eco, 171-174).

Los rasgos de estilo característicos de la narrativa antropológica de Recasens son el extremado detallismo de la descripción, la mezcla de formas discursivas que manifiesta la mutación disciplinaria, o sea, la modificación de las reglas, modalidades, materias y procedimientos de conformación de textos de una disciplina artística, científica o filosófica, provocada por el traslado desde una u otras disciplinas de la misma o distinta condición; el resultado es la confusión de ámbitos disciplinarios, géneros y tipos discursivos (Carrasco y Alvarado, 10-11).; en este caso son la superposición de narración y diálogo dramatizado, emotividad, subjetividad, en la construcción del narrador, junto con la rigurosidad de la elaboración científica. Su técnica consiste en relatar hechos etnográficos sustentados en etnología social humanista, con los recursos de estilo propios de la narrativa literaria moderna y contemporánea.

En los diarios de viaje se manifiesta la descripción detallista, minuciosa, incansable, de elementos observados por el investigador de campo, que pueden servir de base en fecha posterior a una teoría, artículo, monografía, en ella se ve la mano del profesional preparado teórica y técnicamente para hacer obra etnográfica o literaria, o ambas. Un ejemplo es este:

Vamos en una camioneta que nos lleva por el camino a Pichilemu. y luego de unos cuarenta y cinco minutos nos deja en la puerta de un predio. Nos bajamos, ayudo con unos bultos y tomamos un camino interior que nos lleva hacia un sendero y poe bajamos hasta el campamento. Se trata, según puedo apreciar a primera vista, de un caserío que está en un proceso de aldeización. El pequeño estero que se forma de una vertiente, que al llegar a la playa se torna arenoso, separa en dos la disposición de los 'rucos'. Me informan que al costado sur viven las dos familias que tienen una mayor antigüedad en la ocupación del sector y que al otro lado están las familias más nuevas. Es al lado norte en donde la configuración creada por la disposición de los 'rucos' me produce la sensación de 
una aldeílla. Ahí se abren pasajes estrechísimos que separan los 'rucos' de este a oeste, y un pasaje más ancho que cruza sinuoso los 'rucos' de norte a sur (79).

Detallada como descripción científica rigurosa, al tiempo que hermosa en cuanto narración literaria, esta descripción tiene dignidad suficiente para compararse con páginas relevantes de la narrativa moderna.

Otra técnica particular es la superposición de textos de origen variado y hasta heterogéneo en forma de collage, provocada por la incorporación de párrafos y a veces páginas o capítulos de carácter definidamente metatextual, reflexivo, intertextual, retórico, de intención artística, diálogos dramáticos, en páginas 98-99 y 147-154, con otros discursos referenciales, denotativos, puramente informativos, reflexivos. También hay momentos de intensa emotividad a menudo motivados por una aguda sensibilidad social:

Después de un tiempo regreso a lo Valdivia. Me acerco con no mucha seguridad a una puerta entreabierta/.../ Me responde que doña María Odilia falleció. Y frente al desconcierto que demuestro, me cuenta que ella murió de esas enfermedades que tienen los viejos en esos campos, que sin atención ni remedios, Dios se los lleva rápido para que no sigan sufriendo. Me quedo un instante parado ahí, sin saber qué decir ni hacer /.../ Salgo al camino y me detengo ante las salinas. Pero ¡qué pena! ¡Cómo pudo la muerte vencer aquella fortaleza que emanaba de la señora! Pienso que tal vez, porque su cuerpo colaboró con la muerte para doblegar su espíritu noble y valiente. Sí, eso debió suceder. Que el cuerpo perdió su batalla y se rindió ante el frío y la humedad, confabulados, que abrieron paso a la artritis para que morara dueña y señora en sus doloridos huesos iQué sufrimiento habría...! Años y amaneceres amasando y cociendo al horno el pan de cada día, para luego caminar kilómetros envuelta en la bruma y dejarlo en otras manos... Se me ocurre pensar que ante su apuro, su necesidad apremiante, alguien altanero respondió: 'no hay bencina' o 'no está el chofer' (Recasens, 106-107).

$\mathrm{Al}$ mismo tiempo, sobre todo en la narración, es decir, la aparición de un sujeto narrador en el enunciado textual, es muy perceptible la interacción de sectores, idiolectos y descripciones en que se intersectan la precisión, la neutralidad y el rigor en el uso de la frase y la referencialidad, con la emotividad que surge de la sensibilidad, el gusto cultivado y la sensorialidad entre otras expresiones estetizantes:

Los mariscadores de antes no usaban los trajes especiales que utilizan los buzos de ahora/.../ De esa época me viene a la memoria doña Rosa Tuta, una mujer de unos sesenta años, que iba a sacar machas al mar con otras mujeres más jóvenes/.../ Cada una de las mujeres llevaba un quínimo amarrado a la cintura y en la mano un palo grueso, como un bastón largo. Hincaban el bastón en la arena, se tomaban de este con las dos manos y, estirando las nalgas hacia atrás, comenzaban a mover sus talones al mismo tiempo, de izquierda a derecha y de derecha a izquierda, y así sucesivamente, tratando que poco a poco se fueran hundiendo en la arena. Vistas desde fuera, parecía que estuviesen danzando con un ritmo suave y cadencioso, de mucha gracia y belleza, una danza en la que los 
brazos apenas se movían de un lado para el otro mientras las caderas se desplazaban ampliamente a un lado y luego al otro. Los largos vestidos viejos que se ponían para entrar al agua, una vez mojados, se les pegaban al cuerpo ofreciendo contornos firmes de hermosas líneas/.../Pero doña Rosa Tuta no era de las que se asustara por algunas olas más altas de lo común. Era como un árbol plantado en la mitad del banco y no había mar que la asustara y la pudiera mover de ahí, hasta no haber sacado a lo menos veinte docenas de machas. En ese cuerpo endurecido por los embates del viento y el mar, habitaba una sonrisa dulce, como venida de otra parte (68-69).

\section{CONCLUSIONES}

Pueblos de mar. Relatos etnográficos podría ser perfectamente el nombre de una novela o conjunto de cuentos realista por su carga de referencialidad, su apego a hechos verosímiles y veraces, costumbrista por el detallado modo de describir los aspectos característicos de una región, zona, lugar, modo de trabajo, de autores como Mariano Latorre, Luis Durand, Enrique Valdés, y tantos otros. Al mismo tiempo, narración literaria que revive escenas de familias y comunidades laborales, grupos humanos vinculados con el mar y sus oficios y productos. Se trata, como hemos dicho, de un texto que puede leerse como literatura y/o como etnografía.

¿Por qué es literatura y/o etnografia?... Porque es un texto mutante que incluye antropología, literatura, sociología, historia, teología bíblica, en otras palabras, un texto complejo, descriptivo, narrativo, dialógico, mezclado y superpuesto con narración, descripción y apertura del narrador que va ordenando en secuencias las historias contadas, que remiten a grupos mediante las voces de personajes individuales. Especie de novela, mezclada con elementos etnográficos comunes a antropólogos y arqueólogos, donde destaca la persona del narrador, quien habla de los otros y de sí mismo, de lo que hace, lo que siente, sin dejar de mostrar el espacio de mundo que forma parte de su investigación: los pueblos de mar.

Se percibe una relación intensa entre narrador y autor, característico de la escritura social referencial: el autor es el que valida la información, el conocimiento, porque perfectamente podría inventarlo, para lo que sirve la literatura. Esta ambivalencia es propia de la literatura antropológica, incluye a los sujetos de la enunciación que son una mezcla de ficción y referencialidad, por lo demás como muchos relatos literarios: pensemos en la novela histórica, ciencia-ficción, la narración psicológica, de aventuras, sentimental, de viajes, entre otras. En síntesis, un texto que es simultáneamente literario novelesco y etnográfico, ambivalente en los niveles básicos de la narración y de la historia de estos pueblos de mar.

Pueblos de mar..., nos ha situado en la estadía de un antropólogo escritor en comunidades de pescadores, algueros, buzos, salineros, dejando implícita su llegada y sugiriendo el retorno que culminará en reflexión profesional y el trabajo posterior de escritura en que el viaje terminará en literatura, rompiendo la norma de veracidad científica. 


\author{
Universidad Austral de Chile* \\ Facultad de Filosofía y Humanidades \\ Instituto de Lingüistica y Literatura \\ Valdivia (Chile) \\ icarrasc@uach.cl
}

\title{
OBRAS CITADAS
}

Augé, Marc. El sentido de los otros, Actualidad de la antropología. Trad. Charo Lacalle y José Luis Fecé. Barcelona: Ediciones Paidós Ibérica, 1996.

Benjamin, Walter. El Narrador: Introducción, traducción, notas e índices de Pablo Oyarzún R. Santiago de Chile: Ediciones/Metales Pesados, 2011.

Carrasco, Iván; Alvarado, Miguel. "La literatura antropológica en Chile: fundamentos". Estudios Filológicos 46 (2010):9-23.

Colombi, Beatriz. Viaje intelectual: Migraciones y desplazamientos en América Latina (1880-1915). Rosario: Beatriz Viterbo Editora, 2004.

Cortázar, Augusto Raúl. Folklore y Literatura. Buenos Aires: Eudeba, 1967, $2^{\text {a }}$ ed.

Eco, Umberto. "Sobre el estilo", en Sobre literatura. Trad. Helena Lozano M. Barcelona: RqueR Editorial, 2002:171-188.

Genette, Gérard. Umbrales. Trad. Susana Lage. México: Siglo Veintiuno Editores, 2001.

Filinich, María Isabel. La voz y la mirada: Teoría y análisis de la enunciación literaria. México: Plaza y Valdés, SA de CV Editores, 1997.

Martínez Bonati, Félix. La ficción narrativa: Su lógica y ontología. Santiago: LOM Ediciones, 2001.

Mignolo, Walter. Teoría del texto e interpretación de textos. México: Universidad Nacional Autónoma de México, 1986.

Morales, Leonidas. La escritura de al lado: Géneros referenciales. Santiago: Cuarto Propio, 2001.

Recasens, Andrés. Pueblos de mar: Relatos etnográficos. Santiago: Bravo y Allende Editores, 2003. 